\title{
APLICACIÓN DEL PSICOANÁLISIS EN LA EDUCACIÓN
}

\author{
Martha Isabel Barrero Galindo \\ Docente Universidad Surcolombiana \\ mbarrero65@gmail.com
}

Hacer referencia a la posibilidad de aplicar el psicoanálisis a la educación motiva discusiones amplias. Este escrito hará referencia a las posturas que defienden dicha posibilidad para establecer posteriormente, desde el enfoque de la relación de entrecruzamiento, la manera como los conceptos de sujeto, el yo, inconsciente, pulsión, el estadio del espejo, clivaje, identidad, síntoma y niño se pueden aplicar al campo de la educación y específicamente a la pedagogía.

Una de las primeras posturas que va a aparecer en torno a este tema sostiene que no es posible crear una pedagogía psicoanalítica y más aún pretender la complementariedad entre la teoría psicoanalítica y educación; Millot afirma que la teoría analítica es no concluyente en lo que concerniente al campo de la educación y Baietto sostiene que el psicoanálisis para quien enseñar no puede ser una actividad basada en una teoría o una doctrina. (MOSCONI, 2008. P 182).

De acuerdo a esta postura, el lugar del psicoanálisis no el mismo que el de la pedagogía, pues este no se ocupa de las relaciones grupales 0 individuales en las instituciones 0 en los procesos educativos escolares, su lugar es en la clínica. La teoría psicoanalítica no se corresponde tampoco con las teorías sociales ni humanísticas, porque parte del reconocimiento del inconsciente como la piedra angular a donde refieren todas y cada una de las coordenadas teóricas que produce y porque no aspira a constituirse en ciencia de ningún tipo. "El psicoanálisis no representa la forma teórica de presentar otro humanismo. Mientras las diversas teorías y filosofía intentan llenar, obturar con conocimiento nuestros interrogantes, el psicoanálisis se niega a sí mismo el carácter de saber total, es un saber que estimula la falta para dar paso al sujeto. El psicoanálisis busca de una manera distinta a las otras ciencias dar cuenta de la constitución del sujeto". (JIMENEZ, 2002. P 91-92).

Alvarado sostiene que la aplicación del psicoanálisis a la educación requiere de una solidaridad entre ambas teorías de conocimiento, implicando que el investigador (a) conozca ambos campos de aplicación. Esta propuesta requiere comprometerse consigo mismo respecto de la aplicación del psicoanálisis a la educación en la experiencia práctica. Es necesario que el maestro "adopte una posición teórico-reflexiva que permita un compromiso con una práctica educativa que reformula a su vez el ideal de la pedagogía tradicional porque el psicoanálisis devela las ilusiones y evidencia las fracturas (de este ideal)". Es necesario entonces, cuidar la rigurosidad teórica al importar cualquier concepto de un campo de conocimiento a otro, pues existe el riesgo de desvalorizar lo que éste significa (ALVARADO, 2005. Volumen 5. P. 10-11).

Mosconi (2008. P 182- 183) al referirse a la aplicación hace una distinción en el sentido de una aplicación práctica y una ciencia aplicada; la primera supone que se pueda encontrar en la teoría analítica un saber por naturaleza capaz de esclarecer las prácticas educativas y docentes e incluso transformarlas, sin embargo como el fin de la educación o de la enseñanza no es el de la cura analítica no es posible hablar de aplicación "y si se lograra hacer se tendría una teoría descriptiva necesariamente diferente a la de la cura analítica e incluso la pedagogía puede sacar saberes práctico y prácticas diferentes cambiando las reglas técnicas...Para aplicar un saber práctico es necesario saber cuáles son las 
reglas que se aplican o no en el caso dado, como se pueden adaptar a las circunstancias singulares e incluso ante el surgimiento de lo imprevisto, inventar una nueva regla mejor adaptada". La condición para que el psicoanálisis pueda aplicarse a las prácticas educativas es que haga un esfuerzo de conceptualización y de teorización con respecto a las prácticas pedagógicas, semejante al que Freud hizo con respecto a la práctica de la cura. (MOSCONI, 2008. P 188).

En cuanto al psicoanálisis como ciencia aplicada a la educación la considera el autor como posible, puesto que sólo los conocimientos en psicoanálisis de la educación podrán proveer a las prácticas educativas y de enseñanza los datos que permitan construir en este campo un saber práctico, no obstante "La adquisición del puro saber teórico, metapsicológico, no basta para hacer un analista practicante si está no se origina en ese saber interior que el analista construye en el espacio de su propia cura, de la misma manera para el pedagogo practicante, la adquisición de un saber teórico psicoanalítico sobre la práctica pedagógica" (MOSCONI, 2008. P 188).

Para Elgarte (2009.Vol. VI N 6. P. 318 - 319) el discurso psicoanalítico y el discurso pedagógico son dos campos del conocimiento, con diferentes objetos de estudio pero con algo en común: ambos operan con sujetos y con la palabra. "El psicoanálisis como praxis tiene un campo de acción restringido al encuentro entre un analista y un paciente en la intimidad de una sesión. No obstante, el cuerpo teórico psicoanalítico puede entrar en discusión e interacción con otros saberes e intentar realizar articulaciones y contribuciones. Considero que el psicoanálisis logra aproximarse al campo pedagógico desde los conceptos básicos de su teoría: sujeto, inconsciente, pulsión, deseo, transferencia, Complejo de Edipo, ley, castración, función paterna, identificación, entre otros". El autor propone para el psicoanálisis una relación de colaboración con la educación, una relación de aporte desde una perspectiva interdisciplinaria, a partir de sus conceptos fundamentales, tendiendo a hacer entrecruzamientos, promoviendo puntos de interrogación y reflexión, señalando ciertas condiciones y límites del proceso educativo en tanto se considere al Sujeto del inconsciente. (ELGARTE, 2009.Vol. VI N 6. P.326).
Teniendo en cuenta esta relación de entrecruzamiento, podemos establecer que la educación nos incorporarnos en un cierto orden simbólico; trabajo que no podría ser realizado sin el lenguaje; puesto que no hay cultura, educación y sujeto sin lenguaje. La educación no es instintiva, no obedece a un registro natural genético que nos obliga a aprender ciertas cosas a fin de sobrevivir; por lo tanto todo acto educativo es pulsional . El maestro busca llenar al alumno de conocimientos, mientras el alumno busca satisfacer la pretensión del maestro, aprendiendo en plena correspondencia del mandato social. (JIMENEZ, 2002. P 92-93).

Jiménez (2002. P 112) explica que "el profesor, juega con la supuesta posesión del saber, sin adivinar que éste también le ha sido robado, es decir, que ya no sigue ahí. Los alumnos se preguntan entre ellos, copian de sus libros y de los cuadernos de los otros a fin de averiguar dónde está ese saber inaccesible, los jurados siempre apuntan hacia el lugar de la falta, lo que le falta a la tesis y que hacen saber al sustentante, aquí se encuentra un desplazamiento que sufre un significante, el saber, y la posición que ocupan distintos sujetos respecto a éste. Simbólicamente lo robado representa el lugar de ese saber que no se sabe, transmitido en clase, que a su vez provoca la angustia y sudo de los ingenios llevando desde la transferencia hasta la paranoia a los sujetos envueltos en la materia educativa".

El acto pedagógico opera entre sujetos, lo que implica desde el psicoanálisis distinguir entre el Sujeto y el yo. El sujeto es de entrada un Sujeto dividido entre consciente e inconsciente y se produce en el interior de una trama intersubjetiva, en el Otro del lenguaje. Entonces, si el sujeto no es el yo consistente de la identidad, no es el hombre pleno de la psicología tradicional, ello nos conduce al revolucionario descubrimiento freudiano del inconsciente (ELGARTE, 2009. Vol. VI N 6. P. 319).

Si aceptamos al sujeto de la educación como sujeto del inconsciente y a éste como el discurso del Otro, entonces reconoceremos que el sujeto no habla por sí mismo sino que, por estar inmerso en el lenguaje, éste lo predetermina y le posibilita su relación con los demás sujetos. El discurso educativo tiene como sustento al lenguaje y pretende ante todo aludir al ausente, lo que falta, lo que no se sabe. La teoría 
educativa debe por tanto formularse en el encadenamiento de los significantes que se enseña y no en algo que está más allá de la palabra. El psicoanálisis nos enseña que el dominio de todo discurso está en los significantes, y no en las cosas 0 en sus significados. (JIMENEZ, 2002. P 111).

Según Jiménez, (2002. P 97, 99-100) para analizar lo educativo es necesario fijarse en la causa del inconsciente y ello implica reconocer que todo saber es incompleto, insuficiente e infinito. Aunque paradójicamente la realidad y los mecanismos que tenemos para comprenderla se nos ofrecen como completos, suficientes y finitos. Toda demanda social se funda en la creencia de su posible satisfacción, en la posibilidad de la solución. El psicoanálisis enseña que esto es imposible, que las utopías pueden tener otra función más allá del intento vano de querer realizarlas. La teoría psicoanalítica nos hace pensar en un sujeto que más allá de encontrarse como individuo, (indiviso) se percibe en y desde el Otro como inacabado, incompleto, insatisfecho y deseable. Como un sujeto en falta.

Freud considera a lo inconsciente como un sistema regido por leyes, otra lógica de operar el psiquismo que a partir de allí ya no puede asimilarse a lo consciente; es un inconsciente eficaz, indomable por la voluntad consciente y que se produce en los síntomas, actos fallidos, sueños. Al destronar a la conciencia como única instancia de conocimiento, esto pone un límite a los intentos de programación pedagógica. El inconsciente no aprende, no es mensurable ni evaluable. Entonces el sujeto del psicoanálisis, Sujeto del inconsciente, es diferente de un supuesto sujeto del conocimiento, donde se le otorga prevalencia a lo voluntario consciente y se considera a lo intelectual como una entidad independiente y recortable. Desde el psicoanálisis pensamos que lo intelectual no es una aptitud autónoma, sino que depende de la dinámica psíquica, de la trama significante del sujeto. (ELGARTE, 2009. Vol. VI N 6 . P. 320). La educación, a pesar de estar centrada en la conciencia, resulta un acto signado por un inconsciente previamente estructurado, de esta manera los problemas de enseñanza aprendizaje no siempre obedecen a cuestiones didácticas .

La educación en sus diversas formas aparece generalmente como un acto consciente relacionado con la enseñanza-aprendizaje; sin embargo, los esfuerzos por transmitir exitosamente los contenidos de la educación muestran permanentemente formas de resistencia de los sujetos de la enseñanza inexplicables pedagógicamente. Aceptar la educación como síntoma nos permite reconocer que ahí donde la enseñanza aprendizaje fracasa, se manifiesta un síntoma; no basta estar al tanto de las necesidades y métodos de enseñanza para que éstos actúen inmediatamente sobre las carencias educativas. Por supuesto que no se trata del llamado curriculum oculto, nada menos indicado para entenderse esta noción de síntoma. Todo este carácter sintomático de la educación no podría ser entendido sin tratar de aproximarnos a la noción de transferencia. (JIMENEZ, 2002. P 103-104).

El yo por su parte, está constituido gracias al lazo social, el cual permanece en conflicto permanente, sólo soportable mediante el autoengaño. El estado del espejo es el formador de la función del yo, es el momento en el que el niño se reconoce a sí mismo, es el momento de la construcción de la identificación, identificación de uno mismo en términos del otro, es el primer paso para la constitución del sujeto.

Para Lacan, el pasaje de lo imaginario a lo simbólico es una abstracción teórica que apunta a un determinado orden lógico y no es estrictamente cronológico. Desde el momento de su nacimiento, y aun antes, el niño está inserto en una red simbólica construida por sus padres y su familia. El nombre del niño es a veces elegido antes de su nacimiento y su vida está entretejida, en la imaginación de los padres, con una mitología familiar preexisten. Este marco está destinado a influenciar su desarrollo psíquico. Incluso las imágenes con las que nos identificamos en el estadio del espejo derivan del modo en que nuestros padres nos ven y están estructuradas lingüísticamente, lo que explica por qué el estadio del espejo tiene lugar en torno al periodo en que el niño es inserto por primera vez en el lenguaje y comienza a desarrollar sus propias habilidades lingüísticas. (Stavrakakis, 2007. P. 41).

El estadio del espejo según Jameson (1995. P. 20) para Lacan "marca una brecha fundamental entre el sujeto y su propio self o imago que nunca puede ser superada. Esta forma sitúa la instancia del yo, aun desde su determinación social, en una línea de 
ficción, irreductible para siempre por el individuo. El estadio del espejo que es la precondición para el narcisismo primario, es también, debido a la brecha igualmente irreductible que abre entre el niño y sus semejantes, la fuente misma de la agresividad humana; y en efecto, una de las características originales de la enseñanza de Lacan".

Si lo que la educación pretende es reforzar el lazo social que se ha establecido desde los primeros meses en que el niño se mira frente al espejo del otro, la función del estadio del espejo se nos revela entonces como un caso particular de la función del imago, que establece una relación del organismo con su realidad. El estadio del espejo es la función simbólica en la que Lacan describe cómo el niño mira realmente por primera vez su imagen, refiriéndose a la representación que el infante produce de sí mismo al verse en el otro. Teniendo en cuenta esto, los primeros espejos son sin duda los padres, posteriormente y de un modo muy diferente lo serán los maestros. (JIMENEZ, 2002. P 100-101).

Para que durante el estadio del espejo se pueda constituir el yo se hace necesario el clivaje, es decir, separar al individuo del deseo de la madre, se le escinde de ella; papel que es impuesto desde la función paterna; en este momento es impuesta la ley. Para Jiménez (2002. P 102) en el caso de la educación, la escuela no representa la ley, es la ley misma, es el espacio de desplazamiento de los significantes, determinante e integradora del sujeto en la sociedad.

La identificación constitutiva del yo, es un proceso indispensable para la construcción de lo imaginario y como tal no cesa nunca, en tanto jamás estamos totalmente construidos. Nos armamos y desarmamos montando diferentes escenas en el mundo y en este proceso, el docente cumple un papel fundamental como modelo de identificación para el alumno, es como un apoyo para la construcción de un soporte, de un montaje fantasmático; pero tendrá que estar advertido de no encarnar este lugar próximo al ideal, pues puede correr el riesgo de buscar crear súbditos sumisos. La identificación también puede operar en la transmisión de saberes, haciendo que se adquieran en un sentido hipnótico, sin cuestionamiento ni interrogación, sin efectos subjetivantes en el discurso. (ELGARTE, 2009.Vol. VI N 6. P. 321).
La identidad es retomada en la educación a partir de los planes y programas de estudio, pero al hacer referencia a ello no se hace alusión a ella como conjunto de signos o símbolos llamados nacionales o familiares, sino a la manera como estos planes construyen una identificación previa que constituye al sujeto, una identificación imaginaria que posteriormente devendrá en simbólica. La identidad vendría siendo uno de los bienes preciados de la educación, entendida como "el encuentro definitivo con mi yo real, mis valores, mis deseos, destinada a encontrarse con sí mismo, con la felicidad como plenitud, que garantiza el equilibrio y la armonía necesarias para un bienestar social". (JIMÉNEZ, 2002. P 102).

El educador ejerce su acción pedagógica en el contexto de una formación social y concretiza en sí, una red simbólica de representaciones asociadas con una autoridad (pedagógica), como una especie de relación arquetípica con las autoridades de la infancia. (ALVARADO, 2005. Volumen 5. P. 11).

Finalmente, existe una barrera con la cual se encuentra todo maestro en el proceso pedagógico y es la de no comprender a los niños porque han dejado de comprender su propia infancia. Para el psicoanálisis no se puede ser maestro sólo mediante el propósito de serlo, o por haber cursado cierto grado de formación, o por ser mayor. La dificultad para ser maestro estaría en un obstáculo constitutivo del hecho de ser adulto: una enajenación; y por ello se concibe al niño como inocente, una tabula rasa abierta al conocimiento; no entienden con quién están tratando, no saben lo que en él ocurre, de manera que no saben lo que hacen. Si los maestros están bien informados, hallarán más fácil reconciliarse con ciertas fases del desarrollo infantil y no correrán el riesgo de sobrestimar las mociones pulsionales socialmente inservibles o perversas que afloren en el niño" es indudable que el niño atraviese una etapa sádica, que retenga las heces, que quiera verificar el sexo de los demás, etc. Si el maestro lo sabe, no sobrestimará esas manifestaciones.

Partiendo de la postura que permite la relación de entrecruzamiento conseguiríamos establecer que el psicoanálisis esclareciera para la educación el camino de las pulsiones, de forma que obre frente a ellas de manera inteligente y haga una profilaxis de la 
neurosis. (BUSTAMENTE, 2009. P. 265). La educación debe ser es una educación para la realidad, ni voluntarista ni moralista sino iluminada y en primer lugar enfocada a la manera como está constituido el hombre. Una teoría psicoanalítica aplicada al campo de la educación debe estar dispuesta no solo a hacer surgir en este campo "preguntas inéditas" por el reconocimiento de la presencia del inconsciente en la práctica educativa, sino que también deberá estar dispuesta a ser modificada por su objeto mismo. (ALVARADO, 2005. Volumen 5. P. 10)

\section{Bibliografía}

MOSCONI, Nicole. De la aplicación del Psicoanálisis a la Educación. En: Deseo Saber y Transferencia. Editorial Siglo XXI Editores. México, 2008

JACCARD, Roland. Freud. Publicaciones Cruz 0., S.A. ¿Qué sé?. México, 2000

JIMENEZ GARCÍA, Marco. Lacan y la Educación. Gómez Sollano, Marcela (compiladora) En: Teoría, Epistemología y Educación: Debates Contemporáneos. Colección Debate y Reflexión. Universidad Autónoma de México. México, 2002.

ELGARTE, Roberto Julio. Contribuciones del psicoanálisis a la educación. Universidad Nacional del Sur. En: Educación, Lenguaje y Sociedad .Vol. VI No 6 (Diciembre 2009)

JAMESON, Fredric. Imaginario y Simbólico en Lacan. Ediciones el Cielo por Asalto. Argentina, 1995.

STAVRAKAKIS, Yannis. Lacan y lo Político. Libros Prometeo. Universidad Nacional de la Plata. Argentina, 2007

SOLER, Colette. Los Ensayos Finales de Análisis. Editorial Manantial. Buenos Aires, 2007

MARIN CALDERON, Norman David. Lacan: Ios Senderos Bifurcados del Deseo. PurdueUnersity. Tesis Doctoral. Estados Unidos, 2007

BUSTAMANTE ZAMUDI0, Guillermo. Investigación, psicoanálisis, educación. Parte II: avance de investigación: Freud, la educación, el sicoanálisis En: Magis. Volumen I. Número 2. Enero-Junio de 2009. Bogotá Colombia. pp. 261-274. 


\section{PAIIEIA Suscolombiana 18}

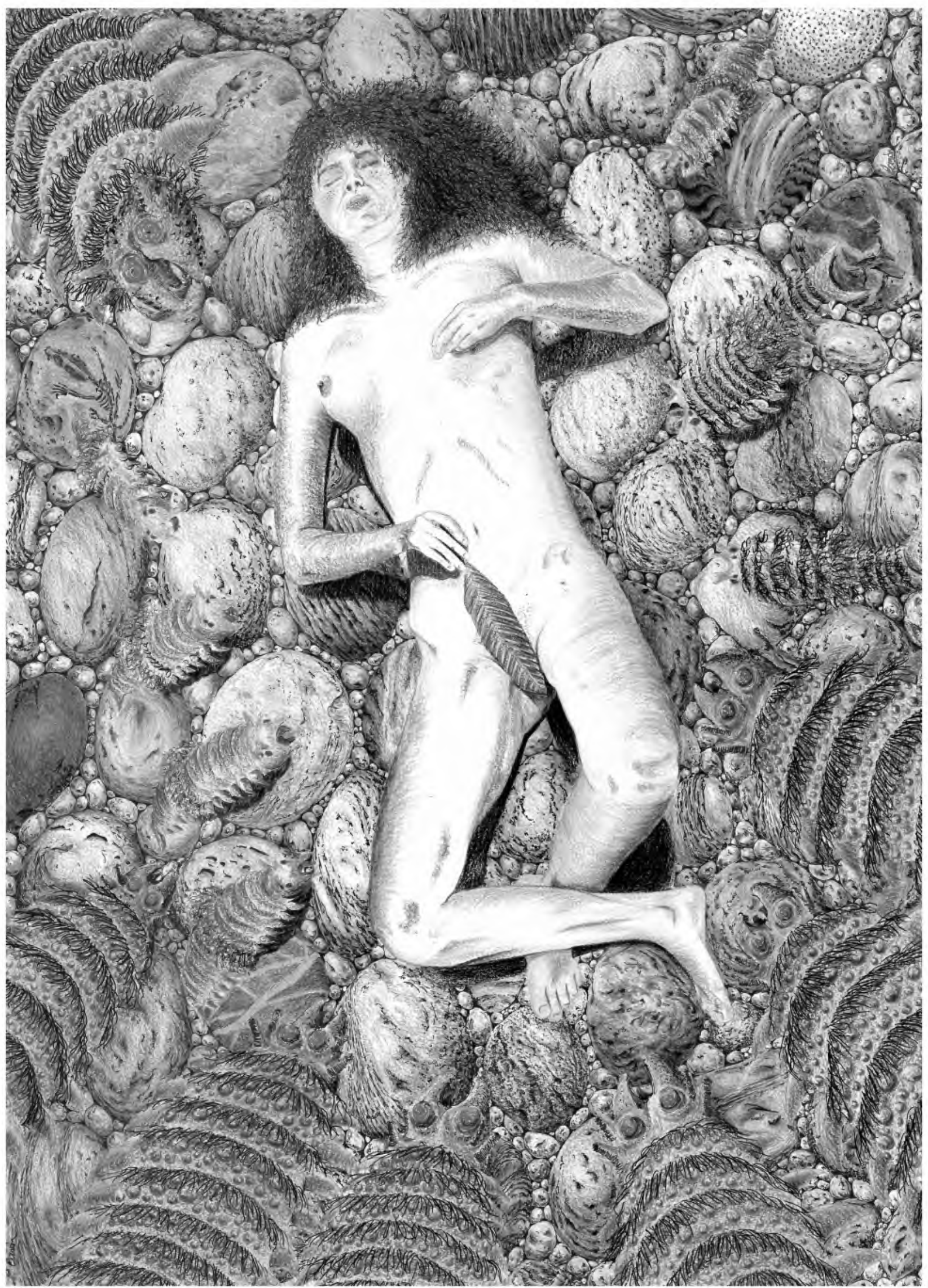

